\title{
Beyond Planning: Implementation, reporting and investment strategies with the CAPER DSS
}

\author{
$\underline{\text { R.A. Kelly }}^{1}$ and A. Locatelli ${ }^{2}$

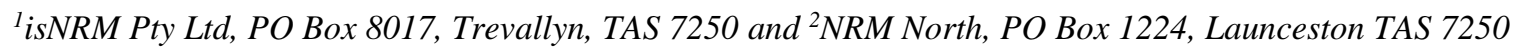

Email: rebecca@isnrm.com.au

\begin{abstract}
The Catchment Planning and Estuary Response (CAPER) DSS has been used successfully over the past decade to aid in the development of Water Quality Improvement Plans, including for Sydney Harbour, Botany Bay, Darwin Harbour and the Great Lakes in NSW. More recently the approach was used to develop a comprehensive WQIP for the Tamar estuary and Esk Rivers catchment in northern Tasmania and simpler plans for multiple smaller catchment and estuary systems in Tasmania. These Plans have provided a blueprint for priority actions to improve water quality, as well as feasible and achievable catchment load and estuary concentration targets.
\end{abstract}

Moving forward there is a need for more detailed investment strategies focused on implementing specific recommendations in the Plan. Increasingly project funding is tied to specified outcomes and there is a need to report not only on the actions undertaken, but also to provide a robust assessment of the likely impacts and benefits of these actions. Given the uncertainties and climatic variations in monitoring data, it is generally not possible to monitor for these changes in the short to medium term (eg. 2 to 10 year period). The CAPER DSS is now being used to fulfil this role, prioritising specific investments in on-ground works considering end goals and desired outcomes as well as the relative costs and benefits of potential investments. A key part of the development of such Investment Plans is developing an understanding of the variety of local priority goals to help focus the implementation of WQIP actions in that region, using a collaborative approach with key stakeholders. The CAPER DSS can then be used to assess investment alternatives against these goals and, in conjunction with discussions about key stakeholder and investor preferences as well as constraints and impediments to adoption, provide a recommended direction for given budget constraints.

This paper outlines the ways in which the CAPER DSS is being used to develop investment strategies, underpin funding applications and support outcome reporting. These are key developments in a strategy to action approach

Keywords: $\quad$ Water Quality Improvement Plan, Decision Support System, stakeholder engagement 


\section{INTRODUCTION}

Water Quality Improvement Plans apply a planning process originally developed by the Australian Federal Government through its Coastal Catchments Initiative. A WQIP provides an ecosystem based approach to integrated water cycle management, supported by science. Water Quality Improvement Plans were originally developed for 12 major estuary systems Australia wide, including the Great Lakes in NSW, Derwent estuary, Botany Bay, Moreton Bay and the Swan Canning Estuary (see for example Swan River Trust, 2009; GLC, 2009; EPA, 2008; Derwent Estuary Program, 2007; SMCMA, 2011). WQIP are designed to:

- $\quad$ Engage state, local government, NRM groups and cooperatively prepare a WQIP and implement interim projects.

- Resolve major impediments to Water Quality planning and management through a catchment management based approach.

- Address the key priority threats to water quality and environmental flows, and establish methods to continuously improve management knowledge and systems.

- Establish governance arrangements that ensure all relevant stakeholders are party to WQIP implementation (adapted from Dept. of Environment, 2011).

The Tamar River estuary is located in North Eastern Tasmania (see Figure 1). The Tamar Estuary and Esk Rivers (TEER) catchments cover nearly $15 \%$ of Tasmania's landmass. The Tamar Estuary extends approximately $70 \mathrm{~km}$ from Launceston to Bass Strait. The region sustains a diverse range of land uses, including grazing, dairy, cropping, plantation and native forestry, mining, heavy industry, urban, rural residential and nature conservation areas. It provides substantial input to Tasmania's economy as well as sustaining key ecological assets and communities. There are 26 sewage treatment plants discharging into the rivers and estuary, many of which are near the end of their lifecycle and in need of upgrade. Parts of Launceston, the major city within the catchment, also use a combined sewer-stormwater system that overflows direct to the Tamar estuary.

A Water Quality Improvement Plan (WQIP) was developed for the Tamar Estuary and Esk Rivers (TEER) catchment area to:

- Provide a comprehensive whole-of-catchment picture of water quality in the Tamar estuary and its tributaries.

- Develop an understanding of the drivers of any water quality issues and the levers that can be used to address these.

- Identify priority activities to address water quality issues.

The TEER Program is a regional partnership between the

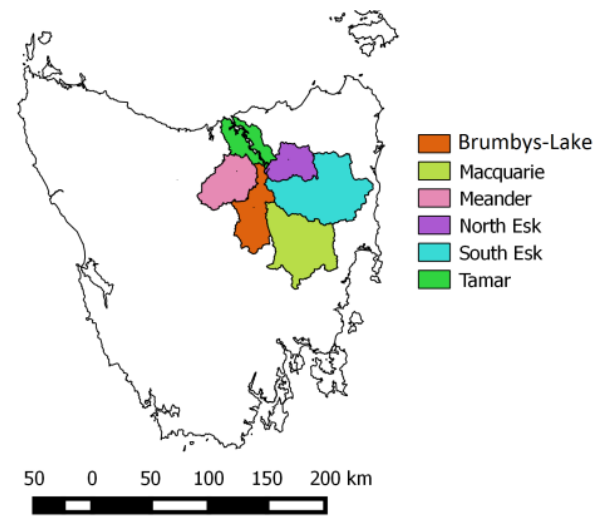

Figure 1. TEER catchment and its subcatchments agencies with a statutory responsibility for waterway management. It is managed by NRM North, the natural resource management body responsible for NRM in Northern Tasmania. The Program includes relevant Local and State governments, Hydro Tasmania and TasWater. In 2013, the TEER program embarked on the development of a Water Quality Improvement Plan (WQIP) to integrate scientific investigations previously undertaken for the catchment and estuary, and develop a long term vision for the catchment and estuary in collaboration with the community.The WQIP was launched in December 2015 with strong support from TEER partners. Since that time the focus of NRM North and other TEER partners has moved on to implementation of the WQIP through targeted catchment investments.

\section{WQIP DEVELOPMENT AND THE ROLE OF THE CAPER DSS}

The TEER WQIP was developed over three main phases: Initial scoping; Decision Support System (DSS) and scenario development, and; WQIP and recommendations. Each phase of the plan process involved consultation and engagement with the community and/or key stakeholders, where those engaged could provide suggestions and feedback on the direction and content of the WQIP. In summary:

- $\quad$ Scoping phase - Used stakeholder feedback to clarify the overarching direction of the WQIP. Consultation used several mechanisms - the TEER Program Scientific and Technical Committee; a WQIP Working Group established to provide oversight to WQIP development; workshops with four key 
stakeholder groups formed for the life of the Plan development focused on forestry, agriculture (grazing, cropping and dairy), urban stormwater, and estuary health and ecology (which incorporated researchers, environmental interests and industries such as aquaculture focused on the estuary); one-on-one consultation with key stakeholders who have significant roles in implementation of any recommended actions; and, three community forums and an online survey targeting the general community.

- Decision support and scenario development phase - A Decision Support System, the TEER Catchment Planning and Estuary Response (CAPER) DSS was developed. It was used to test a range of scenarios developed in consultation with key stakeholders. The role of the DSS was to assess the impacts of various management actions, future land use and population scenarios on catchment and estuary water quality. Workshops were run in September 2014 to provide DSS training to key stakeholders, seek feedback on preliminary results and to determine the scenarios to be included in the Plan, including feasible adoption rates adoption for various management scenarios. The TEER CAPER DSS and the process for developing scenario options are described in more detail in Sections 3 and 4 respectively.

- WQIP and recommendations phase - Scenarios selected by key stakeholders for inclusion in the WQIP were analysed in the DSS and included in drafts of the Plan along with preliminary recommendations before being circulated to key stakeholders for comment. Presentations of relevant scenarios and preliminary recommendations were given separately to key stakeholders such as Local Councils and industry groups. Developing consensus on recommendations between relevant key stakeholders was an important part of this phase of the project.

These phases are described in more detail in Kelly and Locatelli (2015b).

\section{THE TEER CAPER DSS}

The CAPER DSS is a decision support system designed to support the development of Water Quality Improvement Plans. The first CAPER DSS was developed for the Great Lakes in NSW to support the Great Lakes WQIP which was launched in 2009 (GLC, 2009). Since then the DSS has been applied to develop WQIPs in Darwin Harbour, Botany Bay, Sydney Harbour, the TEER and, using a simplified approach, to several other smaller catchments in Tasmania. It has been constantly modified and adapted for each of the catchments and estuaries that it has been developed for. It is built on an integrated model that pulls together components representing the links between climate, land use, management practice and catchment and estuary water quality. Different components are included in each new catchment case study to allow for the specific pollutant sources and relevant management actions to be considered. The interface has also been continuously modified to meet the changing needs of new applications.

The TEER CAPER DSS was modified from previous versions based on feedback received from stakeholders during the scoping phase of the project. The integrated model framework for the TEER CAPER DSS is shown in Figure 2. It consists of:

- A metamodel (ie. a simpler empirical model of model outputs), using flow duration curves, derived from a Source Catchments model developed for the TEER catchment (BMT WBM, 2010). This models pollutant loads from subcatchments and local government areas (LGAs) to allow scenarios to be created and analysed on either basis. This model outputs flow, total suspended sediments (TSS), total nitrogen (TN) and total phosphorus (TP) and enterococci.

- A metamodel of the Model for Urban Stormwater Improvement Conceptualisation (MUSIC) model to allow various water sensitive urban design (WSUD) treatment train options to be investigated (McArthur, 2014).

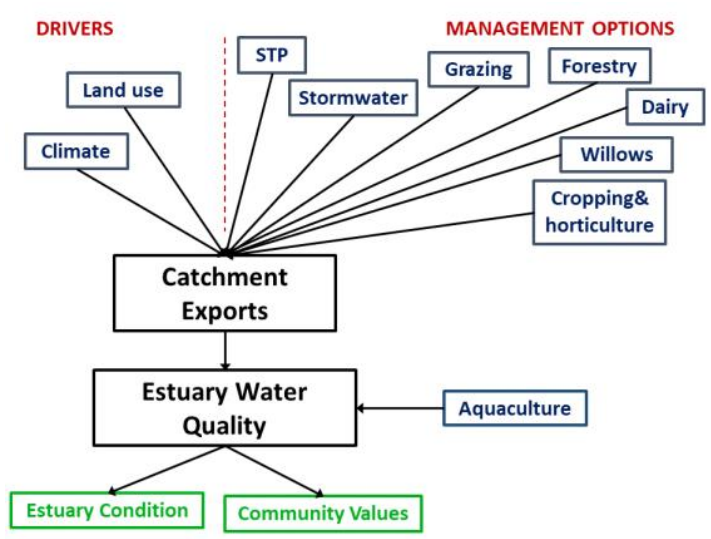

Figure 2. Integrated model framework underlying TEER CAPER DSS

- An empirical model of sewer overflows based on modelling of flows in the combined system areas and assumptions about overflows thresholds and pollutant concentrations provided by TasWater.

- An empirical model of sewage treatment plant (STP) loads based on data provided by TasWater.

- An empirical model of aquaculture operations based on data provided by Van Diemen Aquaculture.

- Models of the impact of management actions in agricultural (cropping, horticulture, grazing and dairy) and production forestry areas on pollutant loads and concentrations using empirical and literature 
information sources including: riparian vegetation and streamside reserves, restricting stock access to stream, improved fertilizer management, groundcover management, irrigation management, effluent management and the management of drains and laneways in dairy areas.

- A metamodel of a receiving water quality model (McAlister et al., 2009) estimating the impacts of changes in diffuse and point source pollutant loads on estuary water quality. This metamodel uses a tracer approach to produce map based spatial impacts on pollutant concentrations in the estuary.

The CAPER DSS is described in more detail in Kelly (2015).

\section{THE PROCESS FOR DEVELOPING LOAD AND CONDITION TARGETS UNDER CURRENT AND FUTURE LAND USES WITHIN THE WQIP}

Numerous scenarios were developed and modelled using the CAPER DSS as part of the development of the WQIP. Multiple stakeholder perspectives were sought using a series of key stakeholder workshops on:

- Actions that stakeholders perceived might be useful to manage water quality and the barriers to adoption of these actions in each major land use.

- The likelihood of these barriers being overcome using various mechanisms such as incentives, education and market forces (eg. the push for accreditation schemes).

- Expected levels of adoption of each action with each mechanism discussed. Key stakeholders quantified these as a percentage of farmers or area (where appropriate), who would be expected to adopt each action given each possible mechanism (eg. education, upfront incentives, maintenance incentives).

- Likely future changes in land use or land management such as irrigation expansion, increased dairy activity though both intensification and extensification, and urban development.

These perspectives were collated and used to underpin scenarios presented in the WQIP. From these, WQIP recommendations and catchment load and estuary concentration targets were also developed in collaboration with key stakeholder groups. The approach to modelling, focused on magnitude and direction of change over large time scales and substantial areas, was explained to stakeholders during the workshops. This meant that conversations with stakeholders tended to focus on the types of options amenable to inclusion in the DSS. Three specific potential sources of pollutants - streambank erosion, septic tanks and smaller point sources in the catchment (eg. salmon hatcheries) for which there was little to no data - were excluded from the modelling. A decision was also made to limit the focus of the WQIP to nutrients, sediments and pathogens, excluding other pollutants such as heavy metals and pesticides as well as in-estuary actions for management of sedimentation (eg. dredging and raking). Scenarios in the WQIP had various purposes:

- To explore the contributions of different point and diffuse sources to pollutant loads.

- To demonstrate the benefits of past management actions, such as the Forest Practices Code.

- To explore the impacts of potential future land use change with and without best management practices.

- To assess the leverage and effectiveness of potential management actions in each land use to help prioritise management actions. These scenarios assumed different levels of adoption for different incentive and education programs, based on key stakeholder feedback on rates of adoption.

A set of long-term (20 to 50 year) catchment load and estuary concentration targets was then developed using the CAPER DSS based on feasible levels of adoption of BMP across all land uses, for both current and future land use and population. While feasible, the targets are aspirational to the degree that major investment and effort is still required to see them met. Targets can be expressed at a whole of catchment or estuary scale, but can also be broken down into subcatchment or Local Government area specific goals. The final WQIP was launched in December 2015 with strong support from Local and State Government and other key stakeholders.

\section{INVESTMENT PLANNING AND OUTCOME REPORTING USING THE CAPER DSS}

The TEER WQIP provides a long term vision for the TEER catchment and the estuary. This vision is necessarily large and expected to be delivered over a long period of time (20+ years). Thus implementation of such a Plan must take place through a series of staged investments that opportunistically access whatever funding sources are available through time as well as leveraging additional funding from these investments. A challenge in implementing Plans of this scope is the need to see outcomes at much smaller timeframes than those proposed in the Plan to justify continued investment. Increasingly there is a requirement for reporting on the outcomes of investment rather funded inputs such as lengths of fencing. This is particularly challenging in water quality management where the benefits from small investments are unlikely to be able to be measured. They are likely to be well within the error margin of most water quality monitoring systems and the influence of climatic variations is likely to obscure the benefits of small investments. Implementation of the entire Plan 
requires long term and large scale financial commitment across a broad landscape and a range of land uses. However our system of funding does not allow for this type of commitment from funding bodies. One way of overcoming this barrier to WQIP implementation is by using a series of targeted Investment Plans focused on achieving specific goals at local scales using the WQIP as a guiding document for selecting actions. Using this approach investors can be sure that their relatively small investment will lead to localised benefits for high value assets of the greatest concern to them, while still contributing to the broader goal of full implementation of the Plan. The CAPER DSS plays an important role in both the development of these Investment Plans and reporting on their expected benefits. These benefits can be quantified in terms of both the local goal of the Investment Plan as well as its contribution to implementation of the full WQIP.

\subsection{Developing an Investment Plan}

The best decision of where to target investments in the landscape and the actions to focus on depends on the goals of the investment. Different actions will have different impacts on the various aspects of water quality and, while all actions can be expected to have local benefits, actions can have very different downstream impacts. Two questions to be asked before choosing an appropriate catchment investment option are:

1. What are the environmental outcomes being sought? Is the focus on sediment accumulation or turbidity? Is there an issue with algal growth that needs to be addressed? Is recreational water quality the issue being targeted? In each of these cases a different pollutant would be targeted - TSS for sediment issues, TN and TP for algal growth, and enterococci for improving recreational water quality.

2. Where are these environmental improvements required? Is the focus on impacts in the upper estuary? Are we seeking benefits for the entire length of the estuary? Are we concerned for drinking water quality from offtakes or other high value local assets in the freshwater system?

The answer depends heavily on the audience being targeted and the source of funds for investment. For this reason it is important to work with groups of stakeholders to develop local priority goals to help focus the implementation of WQIP actions in that region. The CAPER DSS can then be used to assess investment alternatives against these goals and, in conjunction with discussions about key stakeholder and investor preferences and constraints on adoption, provide a recommended direction for investment.

\subsection{Trade-off analysis for Investment Planning using the CAPER DSS}

This section provides a simple illustration of the types of results that can be produced by the CAPER DSS to underpin Investment Planning. For the sake of illustration 3 relatively small budget amounts have been assumed: \$200,000; \$400,000; and, $\$ 600,000$. Actions considered are a) improved effluent management and excluding stock from streams in dairy areas of the Meander Valley and lower South Esk, and b) creating $5 \mathrm{~m}$ riparian buffers with offstream water and fencing to exclude stock from streams in grazing areas of the North Esk. Total costs of implementing key diffuse management actions from the WQIP are over $\$ 100$ million, so these budgets

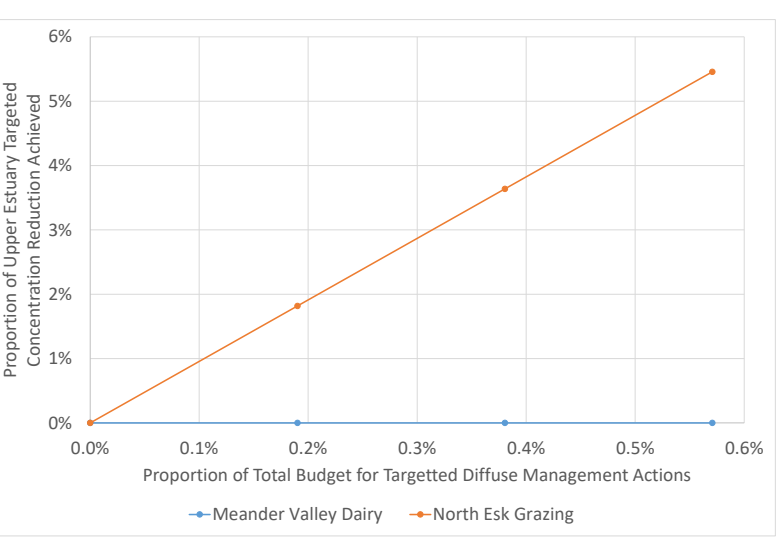

Figure 3. Goal 1 - Impacts of Investment Options on TSS concentrations in the Upper Estuary represent very small investments in implementing the WQIP. Three goals were considered: 1) reducing sediment concentrations in the upper estuary; 2) reducing nutrient inputs to Trevallyn Dam, 3) improving recreational water quality in the estuary. Note that this is a simplistic scenario for illustration purposes only - it has not been guided by stakeholder goals or priorities for management. True investment planning requires iterative consideration of modelled impacts and possible goal statements to develop up well rounded investment proposals that have the support of the local community. Figures 3 to 5 show the contribution each of these investment options makes to achieving the targeted load or concentration reduction from the WQIP relevant to the 3 goals. 
Figures 3 and 4 reflect the location of management actions and the influence this has on goals. The Meander Valley lies above Trevallyn Dam so that reduced pollutant runoff from these areas has the capacity to reduce nutrient loads to the Dam. Impacts from this catchment on the estuary are moderated by the influence of the Dam. The North Esk river drains directly to the Upper Estuary so changes in pollutant loads from this catchment have a more direct impact on estuary water quality. Figure 5 shows the trade-off between the scale of loads and changes in load from management actions and the proximity of actions to the estuary. Dairy areas contribute large proportions of the total enterococci load in the catchment and excluding stock from streams is a key action that can be expected to lead to significant decreases in load, substantial enough to outweigh the closer proximity of fencing works in grazing areas of the North Esk.

These results show both the importance of local goals as a lens for driving investment decisions as well as the substantial impact such investment can make towards 'feasible' targeted improvements at the sites. Depending on the goal, an investment of $\$ 200,000$, less than $0.2 \%$ of the total investment cost of implementing key diffuse actions from the entire Plan, can lead to between $1.4 \%$ and $4 \%$ of the targeted improvement. This represents a good value proposition for investment.

\subsection{Using the CAPER DSS for} outcome reporting post investment

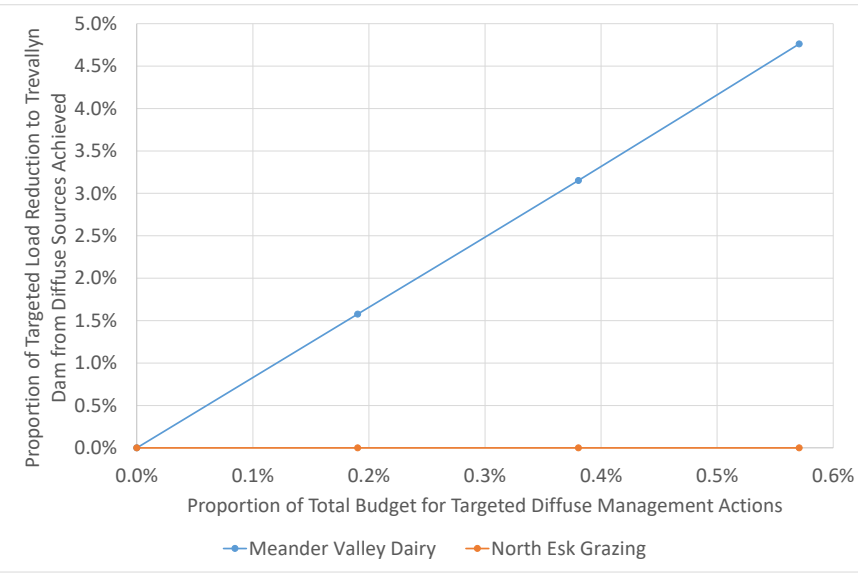

Figure 4. Goal 2 - Impacts of Investment Options on TN loads to Trevallyn Dam

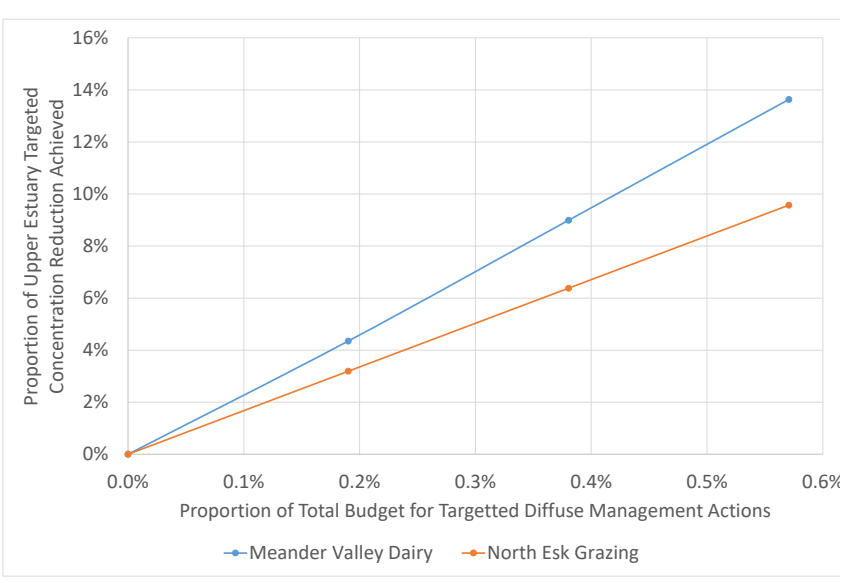

Figure 5. Goal 3 - Impacts of Investment Options on Pathogen concentrations in the Upper Estuary

Governments are increasingly focused on outcome reporting for environmental works. In the past, reporting tended to focus on inputs, such as kms of fencing. More and more, governments are now requiring investments to be targeted to meeting specified objectives and reported against their contribution towards meeting these. This presents a significant challenge for outcome reporting for actions to improve water quality given the difficulties in monitoring changes in catchment water quality directly. For example, climate variability, the inherent uncertainty and issues with accuracy of monitoring, impacts of local actions such as stock access immediately upstream of a sampling point, and the long time it takes for many actions to impact water quality, make monitoring changes in the catchment extremely difficult, if not impossible. Models have the capacity to fill some of this role, allowing estimation of water quality benefits from actions under an 'all other things being equal' scenario. A second role for the CAPER DSS post the WQIP is in such outcome reporting. Outcome reporting using the CAPER DSS can focus on two levels:

- Reporting outcomes for completed actions against the primary goal of the specific investment project, which tends to be shorter term or smaller scale; and,

- Reporting the cumulative benefit of this and other investments made by all partners actively engaged with implementing the Plan. This gives confidence that actions in the catchment are being taken in a coordinated fashion to improve overall catchment water quality and allows for adaptive management.

\section{CONCLUSIONS AND RECOMMENDATIONS}

Too often large scale planning exercises result in catchment plans that fail to find a pathway to implementation. Stakeholders commonly report frustration at a cycle of continuous planning where they are frequently invited to participate in the development of Plans that go on to 'sit on shelves', never implemented. One challenge to 
the implementation of many Plans is their large spatial and temporal scope and the resulting complexity and large budget required for their implementation. Most funding programs are significantly narrower in scope than this investment. In addition, investors need to justify their investment and funding decisions based on likely benefits and be able to assess outcomes once funded actions have been undertaken. This can be a challenge for implementing large plans as the progress towards achieving targets set in the overall plan from modest investments is often very small. One approach to overcoming this barrier is through the development of a series of smaller scale Investment Plans targeting local high value assets and issues over which these smaller scale investments can be expected to have a reasonable level of influence. These Investment Plans need to retain a focus on implementing actions recommended in the WQIP to ensure action is not piecemeal and that these smaller investments continue to contribute to the greater aspirational goals set by the WQIP.

Given its role in developing the WQIP, the CAPER DSS is ideally suited as a tool in the development of such Investment Plans. It can also play a central role in reporting expected outcomes, both in terms of locally targeted goals and their contribution to achieving broader catchment load and estuary condition targets set in the WQIP. Ideally this investment planning takes place within an adaptive management framework, with the modelling used to inform decision investments, and monitoring of experience from these investments used to inform both future modelling and investment decisions. This paper provides an overview of the process of developing such Investment Plans and the way in which the CAPER DSS can be used. Given the large investment made in modelling and decision support platforms, it is important that opportunities to value add to the development of these systems are sought. Central to the use of systems such as the CAPER DSS for investment planning is the trust stakeholders place in them. Experience with the CAPER DSS has shown that the process of model development, where stakeholders play a central and respected role, is at least as important as the model components and methods in the development and maintenance of this trust. Importantly stakeholders must be given a sense of both the capacities as well as the limitations of the modelling. It is important that not only is the model developed 'fit-for-purpose' but that key stakeholders have a good understanding of what this means.

It is important that in developing these Investment Plans the multiple perspectives of stakeholders obtained both through the WQIP development process as well as through targeted Investment Plan development be incorporated. Targeting investments towards achieving outcomes for high priority local issues and assets is key to obtaining the levels of funding required to implement the WQIP. Seeking and valuing key stakeholder insights is crucial to ensuring appropriate and achievable goals are set relative to the fairly short period for which these smaller amounts of funding are generally available.

\section{ACKNOWLEDGMENTS}

The TEER WQIP has been funded through partner contributions to the TEER Program, facilitated through NRM North. Program partners have been generous in their contributions of time, data and expertise into the development of the WQIP and Investment Plans. Thanks also goes to all the stakeholders who engaged in development of the Plan and who continue to be engaged in its implementation.

\section{REFERENCES}

BMT WBM (2010). Tamar Estuary and Esk Rivers Catchment WaterCAST Model: Final Report to NRM North, 2010.

Dept. of Environment (2011). Water Quality Improvement Plans,

http://www.environment.gov.au/water/quality/improvement.

DEP (2007). Derwent Estuary Water Quality Improvement Plan for Heavy Metals, prepared by the Derwent Estuary

Program with support from the Australian Government Coastal Catchments Initiative, Tasmanian State Government and Derwent Estuary Program partnership, June 2007.

EPA (2008). Water Quality Improvement Plan for the Rivers and Estuary of the Peel-Harvey System - Phosphorus Management, Environmental Protection Authority, Perth, Western Australia.

GLC (2009). Great Lakes WQIP: Wallis, Smiths and Myall Lakes, Forster, NSW, Great Lakes Council, Forster, NSW.

LLS (2015). Sydney Harbour Water Quality Improvement Plan, Local Land Services.

Kelly, R.A and Dahlenburg, J. (2011). Botany Bay Water Quality Improvement Plan.

Kelly, R.A. (2015). Using Decision Support for Water Quality Improvement Planning: the CAPER DSS, MODSIM 2015.

Kelly, R.A, A. Locatelli, and M. White (2015a). Water Quality Improvement Plan for the Tamar Estuary and Esk rivers, NRM North.

Kelly, R.A, A. Locatelli, and M. White (2015b). A Plan for Water Quality Improvement in the Tamar Estuary and Esk rivers, MODSIM 2015.

McAlister, T., Patterson, D., Teakle, I., Barry, M. and Jempson, M. (2009). Hydrodynamic Modelling of the Tamar Estuary: Final Report, Prepared for Launceston City Council.

McArthur, J. (2014). WSUD Implementation Decision Support Tool, User Reference Guide, prepared for NRM North by BMT WBM.

Swan River Trust (2009). Swan Canning Water Quality Improvement Plan, Perth, Western Australia. 